\title{
Insights into the characterization of ars genes in the biomining bacterium Acidithiobacillus caldus SM-1
}

\author{
Shuijing Yu, Yangwu Deng, Yonghong Zhao, Changli Liang, Yanhua guo and Xianping Luo* \\ School of Resources and Environment, Jiangxi University of Science and Technology, \\ Ganzhou, Jiangxi, 341000, People's Republic of China.
}

Accepted 3 September, 2012

\begin{abstract}
Acidithiobacillus caldus is an extremely acidophilic, moderately thermophilic, chemoautotrophic bacterium, which has been used to treat gold-bearing arsenopyrite ores. The arsenic resistance system (ars operon) was responsible for arsenic resistance of $\boldsymbol{A}$. caldus. To investigate the characterization of ars genes, we analyzed 12 ars genes in $A$. caldus SM-1 using the bioinformatics database and softwares. Their amino acid composition and physical and chemical characteristics were predicted. Secondary structure simulations revealed that the dominant patterns were predicted to be alpha helix and random coil among the 12 ars proteins. Three-dimensional structure analysis showed that there totally existed three major types of three-dimensional structure of the 12 ars proteins in A. caldus SM-1. Subcellular localization of these proteins indicated that these ars proteins were mainly located in the bacterial cytoplasm, while Atc_0977, Atc_1809 and Atc_m110 were especially localized in bacterial inner membrane. Furthermore, DNA-binding residues in ArsR proteins and binding sites of ArsC-As were predicted. Phylogeny analysis revealed that $A$. caldus, $A$. ferrooxidans, $A$. ferrivorans and $A$. thiooxidans were well-supported group based on ArsB and ArsC sequences data. This bioinformatics analysis of ars genes could help in probing to the arsenic resistance of $A$. caldus SM-1.
\end{abstract}

Key words: Acidithiobacillus caldus, ars gene, acidophile, arsenic resistance, bioinformatics analysis, biomining bacterium.

\section{INTRODUCTION}

Acidithiobacillus caldus is a moderately thermophilic, acidophilic, sulphur-oxidizing, Gram-negative bacterium (Hallberg and Lindstrom, 1994). It lives in extremely acidic environments ( $\mathrm{pH} 1$ to 3 ) typically associated with the bioleaching and natural acid drainage systems. $A$. caldus could increase the arsenopyrite-leaching efficiency in arsenopyrite leaching in combination with Sulfobacillus thermosulfidooxidans (Dopson and Lindstrom, 1999). Continuous-flow tanks, which were used for the bio-oxidation of arsenopyrite concentrates and operated at $40^{\circ} \mathrm{C}$, were dominated by a mixture of the sulphur-oxidizing bacterium $A$. caldus and the ironoxidizing bacterium Leptospirillum ferriphilum (Rawlings,
1999). A. caldus KU was found to be resistant to the arsenical ions arsenate, arsenite, and antimony via an inducible, chromosomally encoded resistance mechanism, and induced $A$. caldus $\mathrm{KU}$ could transport arsenate and arsenite out of the cell against a concentration gradient (Dopson et al., 2001).

The well-characterized microbial arsenic detoxification pathway involves the arsenic resistance system (ars) operon which codes for a regulatory protein (ArsR), an arsenate permease (ArsB), and an arsenate reductase (ArsC). The arsR gene coded for arsenite (As (III))responsive repressor of transcription, the ars $B$ gene coded for an arsenite specific transmembrane pump, 
and the ars $C$ gene coded for an arsenate reductase that converted arsenate to arsenite (Cervantes et al., 1994; Ji and Silver, 1992; Saltikov and Newman, 2003). The response of $L$. ferriphilum to arsenic stress was analyzed and three arsenic response proteins were ars member proteins ( $\mathrm{Li}$ et al., 2010). The arsenic resistance gene cluster of Microbacterium sp. A33 contained an unusual arsRC2 fusion gene, ACR3, and arsC1 in an operon. ArsRC2 negatively regulated the expression of the pentacistronic operon. ArsC1 and ArsC3 were related to thioredoxin-dependent arsenate reductases (AchourRokbani et al., 2010). The chromosomally located arsenic resistance operon from $A$. caldus has been described previously, and it consists of three genes: ars $R$, ars $B$, and $\operatorname{ars} C$ (Kotze et al., 2006). The arsenic operon of transposon origin, TnAtcArs, that carries a set of arsenicresistance genes was isolated from a strain of $A$. caldus (Tuffin et al., 2005). The chromosomal $A$. caldus ars genes were cloned and found to consist of ars $R$ and ars $C$ genes transcribed in one direction, and ars $B$ in the opposite direction. The TnAtcArs was expressed at a higher level, and was less tightly regulated in Escherichia coli than were the $A$. caldus ars genes of chromosomal origin (Kotze et al., 2006).

The ars operon provides arsenic resistance to a variety of microorganisms and can be chromosomal or plasmidborne. However, no studies regards to physical or chemical properties and structural analysis of ars genes in $A$. caldus whole genome were mentioned. Recent description of the whole genome sequences of $A$. caldus SM1 isolated from a pilot bioleaching reactor offers the opportunity to conduct detailed investigation on the characterization of ars genes (You et al., 2011). This study was done to analyze the characterization of ars genes in $A$. caldus SM-1 using the bioinformatics database and softwares.

\section{MATERIALS AND METHODS}

\section{Sources of sequence data}

The sequences (NC_015850, NC_015851, NC_015852 and NC_015853) of $A$. caldus SM-1 were downloaded from National Center for Biotechnology Information (NCBI) genome database, including .faa, .ffn and .ptt files. The ars genes were searched in .ptt file according to annotation information, and then verified by online BLAST searching at NCBI website.

\section{Bioinformatics analysis of ars genes}

Physical and chemical properties of ars proteins were calculated with the help of ProtParam online (http://www.expasy.ch/tools/protparam.html) (Wilkins et al., 1999), related indexes including theoretical pl, molecular weight, formula, aliphatic index and instability index. Prediction of protein secondary structure was carried out via program of HNN: Secondary Structure Prediction Method protocols (Combet et al., 2000) (http://npsapbil.ibcp.fr/cgi-bin/npsa_automat.pl?page=/NPSA/npsa_hnn.html) and transmembrane domains were analyzed by TMHMM Server v.
2.0 (http://www.cbs.dtu.dk/services/TMHMM/). SignalP v. 4.0 (http://www.cbs.dtu.dk/services/SignalP/) and PSORT (http://psort.hgc.jp/form.html) were used, respectively for signal peptide prediction and subcelluar localization (Petersen et al., 2011; Nakai and Horton, 1999). The prediction of three-dimensional structure of ars proteins was carried out with the help of SWISSMODEL online server (Benkert et al., 2011) (http://swissmodel.expasy.org/workspace/index.php?func=modellin g_simple1).

\section{Prediction of DNA-binding residues in ArsR proteins}

Sequence-based prediction of DNA-binding residues in ArsR proteins of $A$. caldus SM-1 was carried out with the help of the DNABR web-server (Ma et al., 2012) (http://www.cbi.seu.edu.cn/DNABR/).

\section{Prediction of binding sites of ArsC-As}

Ars $\mathrm{C}$ sequence was used to PSI-BLAST against the PDB database, so as to retrieve PDB-ID with relevant homology for a specific template. The prediction of molecular modeling of ArsC was carried out with the help of SWISS-MODEL online server (Benkert et al., 2011). The prediction of protein-ligand binding sites of ArsC was carried out via the Q-SiteFinder web-server (Laurie and Jackson, 2005) (http://www.modelling.leeds.ac.uk/qsitefinder/).

\section{Phylogenetic tree construction of ars genes}

Phylogenetic tree was constructed by using MEGA 4.0 software based on the sequences of ArsB, ArsC and ArsR (Tamura et al., 2007). The query sequences of $\operatorname{Ars} B$ and $\operatorname{Ars} C$ in $A$. caldus were BLASTed against the NCBI protein database, respectively. Highly similar sequences from BLAST output were selected for constructing phylogenetic tree.

\section{RESULTS}

\section{Annotation information of ars genes}

Using information retrieval to ars genes, 12 ars genes of A. caldus SM-1 were obtained as shown in Table 1. Among them, Atc_0975 and Atc_0977 genes were coded for ArsC and ArsB proteins, respectively while the others were coded for ArsR protein. Only Atc m066 and Atc m110 were plasmid-borne from the plasmid (NC_015851) of $A$. caldus SM-1. Furthermore, according to BLASTN output, the nucleotide sequence of Atc_0558 shared little or no sequence similarity to any nucleotide sequence in the $n r / n t$ database at NCBI and was considered as specific marker gene of $A$. caldus SM-1, which had potential to be applied in molecular identification of $A$. caldus SM-1.

\section{Physical and chemical analysis of ars genes}

As shown in Table 1, the number of amino acids coded by the 12 ars genes varied from 60 to 435, in which 
Table 1. Annotation information and physical and chemical properties of ars genes in Acidithiobacillus caldus SM-1.

\begin{tabular}{|c|c|c|c|c|c|c|c|}
\hline $\begin{array}{l}\text { Protein } \\
\text { ID }\end{array}$ & PID & Product & aa & $\begin{array}{c}\text { Theoretical } \\
\text { pl }\end{array}$ & $\begin{array}{c}\text { Molecular } \\
\text { weight (kD) }\end{array}$ & $\begin{array}{c}\text { Aliphatic } \\
\text { index }\end{array}$ & $\begin{array}{l}\text { Instability } \\
\text { index }\end{array}$ \\
\hline Atc_0550 & 340781293 & $\begin{array}{l}\text { ArsR family transcriptional } \\
\text { regulator }\end{array}$ & 119 & 7.74 & 13270.3 & 103.28 & 35.14 \\
\hline Atc_0558 & 340781301 & $\begin{array}{l}\text { ArsR family transcriptional } \\
\text { regulator }\end{array}$ & 129 & 8.42 & 14640.9 & 99.15 & 35.93 \\
\hline Atc_0951 & 340781693 & $\begin{array}{l}\text { ArsR family transcriptional } \\
\text { regulator }\end{array}$ & 97 & 10.48 & 10854.8 & 117.63 & 28.91 \\
\hline Atc_0975 & 340781717 & ArsC & 163 & 5.49 & 17525.8 & 89.39 & 51.78 \\
\hline Atc_0976 & 340781718 & $\begin{array}{l}\text { ArsR family transcriptional } \\
\text { regulator }\end{array}$ & 121 & 6.58 & 13417.2 & 93.55 & 43.50 \\
\hline Atc_0977 & 340781719 & arsenic efflux pump protein & 435 & 9.78 & 46770.1 & 137.47 & 37.35 \\
\hline Atc_1751 & 340782493 & $\begin{array}{l}\text { ArsR family transcriptional } \\
\text { regulator }\end{array}$ & 102 & 7.83 & 11493.3 & 102.25 & 54.55 \\
\hline Atc_1809 & 340782551 & $\begin{array}{l}\text { ArsR family transcriptional } \\
\text { regulator }\end{array}$ & 260 & 7.76 & 28931.1 & 90.19 & 45.07 \\
\hline Atc_1895 & 340782637 & $\begin{array}{l}\text { ArsR family transcriptional } \\
\text { regulator }\end{array}$ & 129 & 8.42 & 14640.9 & 99.15 & 35.93 \\
\hline Atc_1903 & 340782645 & $\begin{array}{l}\text { ArsR family transcriptional } \\
\text { regulator }\end{array}$ & 119 & 7.74 & 13270.3 & 103.28 & 35.14 \\
\hline Atc_m066 & 340783691 & $\begin{array}{l}\text { ArsR family transcriptional } \\
\text { regulator }\end{array}$ & 60 & 6.82 & 6848.8 & 102.50 & 40.56 \\
\hline Atc_m110 & 340783735 & $\begin{array}{l}\text { putative ArsR family } \\
\text { transcriptional regulator }\end{array}$ & 254 & 8.39 & 28238.3 & 89.65 & 46.96 \\
\hline
\end{tabular}

Atc_0977 had the most amino acids, 435, and the highest molecular weight, while Atc m066 the least. Aliphatic index analysis illustrated that Atc_0550, Atc_0951, Atc_0977, Atc_1751 and Atc_1903 had high values above 100, which were indicated as hydrophilic proteins. And the others were hydrophobic proteins. Moreover, instability index assay implicated that these proteins with high values above 40 were instable proteins, including Atc_0975, Atc_0976, Atc_1751, Atc_1809, Atc_m066 and Atc_m110, and the others were stable proteins. Most ArsR proteins were instable proteins, and metabolic instability of these proteins may involve into an inducible, chromosomally encoded arsenic resistance mechanism of $A$. caldus SM-1. It is worth mentioning that theoretical isoelectric point ( $\mathrm{pl}$ ) of the majority of ars proteins was > 7 , which seemed to be inconsistent with extremely acido- philic characterization of $A$. caldus SM-1.

\section{Secondary structure simulations of ars genes}

As is illustrated in Table 2, peptide prediction analysis showed that all of the 12 ars genes were non secreted proteins. And only Atc_0977 possessed 11 transmembrane regions by transmembrane prediction. In addition, secondary structure simulations showed that all of the ars genes possessed three patterns, that is, most alpha helix, less random coil, and the least extended strand.

\section{Tertiary structure prediction of ars genes}

The tertiary structure of ars genes were predicted via 
Table 2. Higher structure simulations of ars genes and subcellular localization of ars proteins in Acidithiobacillus caldus SM-1.

\begin{tabular}{lcccccc}
\hline Protein ID & $\begin{array}{c}\text { Transmembrane } \\
\text { region }\end{array}$ & $\begin{array}{c}\text { Alpha } \\
\text { helix }\end{array}$ & $\begin{array}{c}\text { Extended } \\
\text { strand }\end{array}$ & $\begin{array}{c}\text { Random } \\
\text { coil }\end{array}$ & $\begin{array}{c}\text { Bacterial } \\
\text { cytoplasm }\end{array}$ & $\begin{array}{c}\text { Bacterial inner } \\
\text { membrane }\end{array}$ \\
\hline Atc_0550 & 0 & 56 & 15 & 48 & 0.075 & 0.000 \\
Atc_0558 & 0 & 86 & 5 & 38 & 0.282 & 0.000 \\
Atc_0951 & 0 & 60 & 14 & 23 & 0.159 & 0.000 \\
Atc_0975 & 0 & 50 & 15 & 93 & 0.024 & 0.000 \\
Atc_0976 & 0 & 62 & 7 & 52 & 0.160 & 0.000 \\
Atc_0977 & 11 & 256 & 56 & 123 & 0.000 & 0.435 \\
Atc_1751 & 0 & 57 & 13 & 32 & 0.305 & 0.000 \\
Atc_1809 & 0 & 130 & 26 & 104 & 0.000 & 0.157 \\
Atc_1895 & 0 & 86 & 5 & 38 & 0.282 & 0.000 \\
Atc_1903 & 0 & 56 & 15 & 48 & 0.075 & 0.000 \\
Atc_m066 & 0 & 26 & 13 & 21 & 0.227 & 0.000 \\
Atc_m110 & 0 & 128 & 22 & 104 & 0.000 & 0.157 \\
\hline
\end{tabular}

SWISS-MODEL online server. As shown in Figure 1, there totally existed 3 major types of three-dimensional structure, in which Atc 0976, Atc 1809 and Atc m110 made up one class that exhibited similar structure. Atc_0550, Atc_1751 and Atc_1903 were classified into the other class. Atc_0558 and Atc_1895 also exhibited similar structure. In addition, tertiary structure prediction of Atc_0977 found no suitable templates, so its tertiary structure could not be given. These findings implied that ars genes may play different roles in inducible arsenicresistance mechanism in $A$. caldus, which needs further studies.

\section{Subcellular localization of ars proteins}

Presumably, as shown in Table 2, these ars protein members were mainly localized in bacterial cytoplasm of A. caldus SM-1. Seemingly, Atc 0550 and Atc 1903, Atc_0558 and Atc_1895 had similar localization levels, respectively. Especially, Atc_0977, Atc_1809 and Atc_m110 were localized in bacterial inner membrane. These results implied that ars proteins had extensive and delicate localizations in $A$. caldus SM-1 cell.

\section{Prediction of DNA-binding residues in ArsR proteins}

DNA-binding residues in 10 ArsR proteins of $A$. caldus SM-1 were predicted using the DNABR web-server. As shown in Table 3, DNA-binding residues of six ArsR proteins (Atc_0550, Atc_0558, Atc_1809, Atc_1895, Atc_1903, and Atc_m110) contained two cysteine residues, respectively probably provided with the ability to interact with arsenite.

\section{Prediction of binding sites of ArsC-As}

Crystal structure (PDB ID:1JL3-A) of ArsC in Bacillus subtilis was retrieved with relevant homology to ArsC protein of $A$. caldus SM-1via PSI-BLAST searching. Using PDB 1JL3-A as a specific template, PDB file of ArsC protein was obtained with the help of SWISSMODEL online server. With the searching of the QSiteFinder web-server, the structure of binding sites of ArsC model was obtained as shown in Figure 2. There were ten binding active sites in ArsC model, and among of them, second binding site was composed of six residues Leu 52, Arg 55, Glu 56, Tyr 125, Arg 126 and Arg 129 (Figure 2). For ArsC arsenate reductase, three of the basic residues, Arg 60, Arg 94, and Arg 107, are particularly significant because they interact directly with the arsenate and arsenite intermediates (Martin et al., 2001). It implied that the second binding site was binding site of ArsC-As in $A$. caldus SM-1 because the other seven binding sites cannot be provided with Arg residue and the two binding sites (first and tenth binding sites) were provided with only one Arg residue (data not shown).

\section{Phylogeny analysis of ars genes}

Phylogenetic tree was constructed by using MEGA 4.0 software between the sequences of ArsRs in A. caldus. Atc_0550, Atc_1809 and Atc_0558 were strictly clustered with Atc_1903, Atc_m110 and Atc_1895, correspondingly (Figure $\overline{3}$ ). A. caldus, A. ferrooxidans ATCC 53993, and A. ferrivorans SS3 were well-supported group using ArsB sequence data (Figure 4). The three sampled species of A. thiooxidans ATCC 19377, A. ferrooxidans ATCC 53993, Acidithiobacillus sp. GGI-221 formed a supported 
Table 3. Prediction of DNA-binding residues in ArsR proteins of Acidithiobacillus caldus SM-1

\begin{tabular}{|c|c|}
\hline Protein ID & amino acid sequences of $\operatorname{ArsRs}^{\mathrm{a}}$ \\
\hline Atc_0550 & $\begin{array}{l}\text { VRYALFSEVFAALAHPKRLEIIHYLGEGQKNAGELAELISLSKANLSQHLSVLKAR } \\
\text { GLVHCEEKCGIFEHYRLTSPKVLETCEIVRDLILDQMQTTTQLQEALATVVPLR }\end{array}$ \\
\hline Atc_0558 & $\begin{array}{l}\text { TDPRCLVNCFEPGKVAAARMRLEQDESDIKAVVRIFDVLGNRTRLRILLALASEEL } \\
\text { CVCDIAHALNLSISAASHQLRALHDRDWLRMRNDGKMVYYRTDPQKVKQLLSMT } \\
\text { NAFLEARIA }\end{array}$ \\
\hline Atc_0951 & $\begin{array}{l}\text { LSDREIPRVASAIKAIAHPLRYKIICLLSKGEMSMQNLVKAINTSHSNASQHLAMLQ } \\
\text { DSGLVLARKVASRVYYRIRDQRTLNLLAVS }\end{array}$ \\
\hline Atc_0976 & 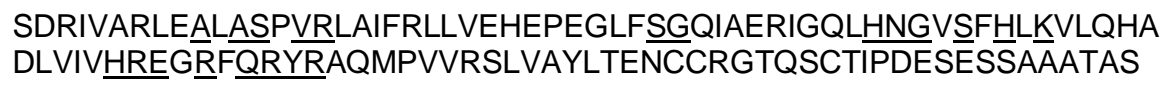 \\
\hline Atc_1751 & $\begin{array}{l}\text { TREEDIEQASRSLKAMAHPLRLKVLCVLGSDEMSVQDIVAAVGTTQSNISQHLAIL } \\
\text { REKEILRARKDANKVYYRVGDPRTLRLISMMSEVFC }\end{array}$ \\
\hline Atc_1809 & 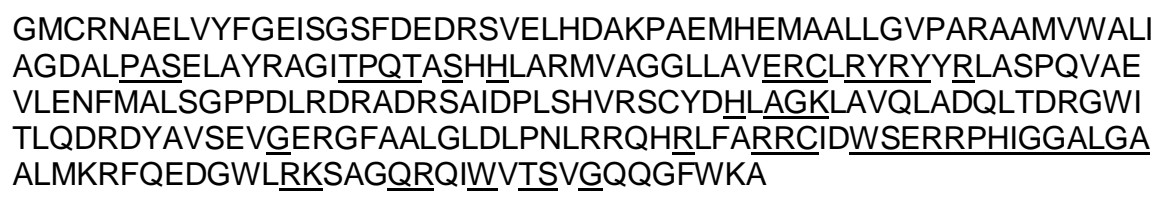 \\
\hline Atc_1895 & $\begin{array}{l}\text { TDPRCLVNCFEPGKVAAARMRLEQDESDIKAVVRIFDVLGNRTRLRILLALASEEL } \\
\text { CVCDIAHALNLSISAASHQLRALHDRDWLRMRNDGKMVYYRTDPQKVKQLLSMT } \\
\text { NAFLEARIA }\end{array}$ \\
\hline Atc_1903 & 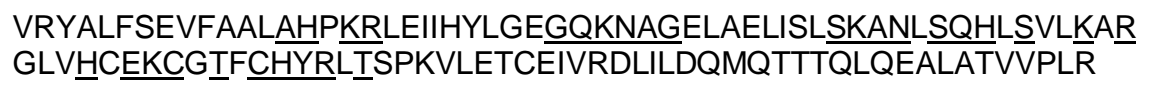 \\
\hline Atc_m066 & ELSIAGASHQLRALHDRGWLHMRNDGKMVYYRLㅇPDALRQVLQEGRIFLE \\
\hline Atc_m110 & $\begin{array}{l}\text { ELVYFGEISGSFDEDRSVELHDAKPAEMHEMALLGVPARAAMVWALIAGDALP } \\
\text { ASELAYRAGITPQTASHHLARMVAGGLLAVERCLRYRYYRLASPQVAEVLENFM } \\
\text { ALSGPPALRDRADRSAIDPLSHVRSCYDHLAGKLAVQLADQLTDRGWITLQDRD } \\
\text { YAVSEVGERGFAALGLDLPNLRRQHELFARRCIDWSERRPHIGGALGAALMKRF } \\
\text { QEDGWLRKSAGQRQIWVISVGQGGFWKA }\end{array}$ \\
\hline
\end{tabular}

${ }^{\mathrm{a}}$ Predicted DNA-binding residues in protein sequences were labeled using the red and underscore.

group with $A$. caldus based on the analysis of ArsC sequence data (Figure 5). These results suggest that the Acidithiobacillus genus seems to share the same evolutionary origin in arsenic resistance system.

\section{DISCUSSION}

Microorganisms have evolved a variety of mechanisms for coping with arsenic toxicity, including minimizing the amount of arsenic that enters the cell, example through increased specificity of phosphate uptake (Cervantes et al., 1994), arsenite oxidation through the activity of arsenite oxidase (Cervantes et al., 1994; Muller et al., 2003). Some microorganisms utilize arsenic in metabolism, either as a terminal electron acceptor in dissimilatory arsenate respiration (Dianne, 1998; Stolz and Oremland, 1999; Huber et al., 2000) or as an electron donor in chemoautotrophic arsenite oxidation (Santini et al., 2000). In this paper, ars genes of $A$. caldus SM-1 coded for ArsB, ArsC and ArsR, implying an inducible, precisely adjustable arsenic-resistance mechanism in $A$. caldus SM-1. Therefore, we had interests in grapevine genome database, with the intent to give bioinformatical support to further grapevine biological researches.

The structure characteristics analysis of ars proteins was of considerable importance for the investigation into biological mechanism of arsenic resistance of $A$. caldus. The ArsC arsenate reductase from E. coli plasmid R773 


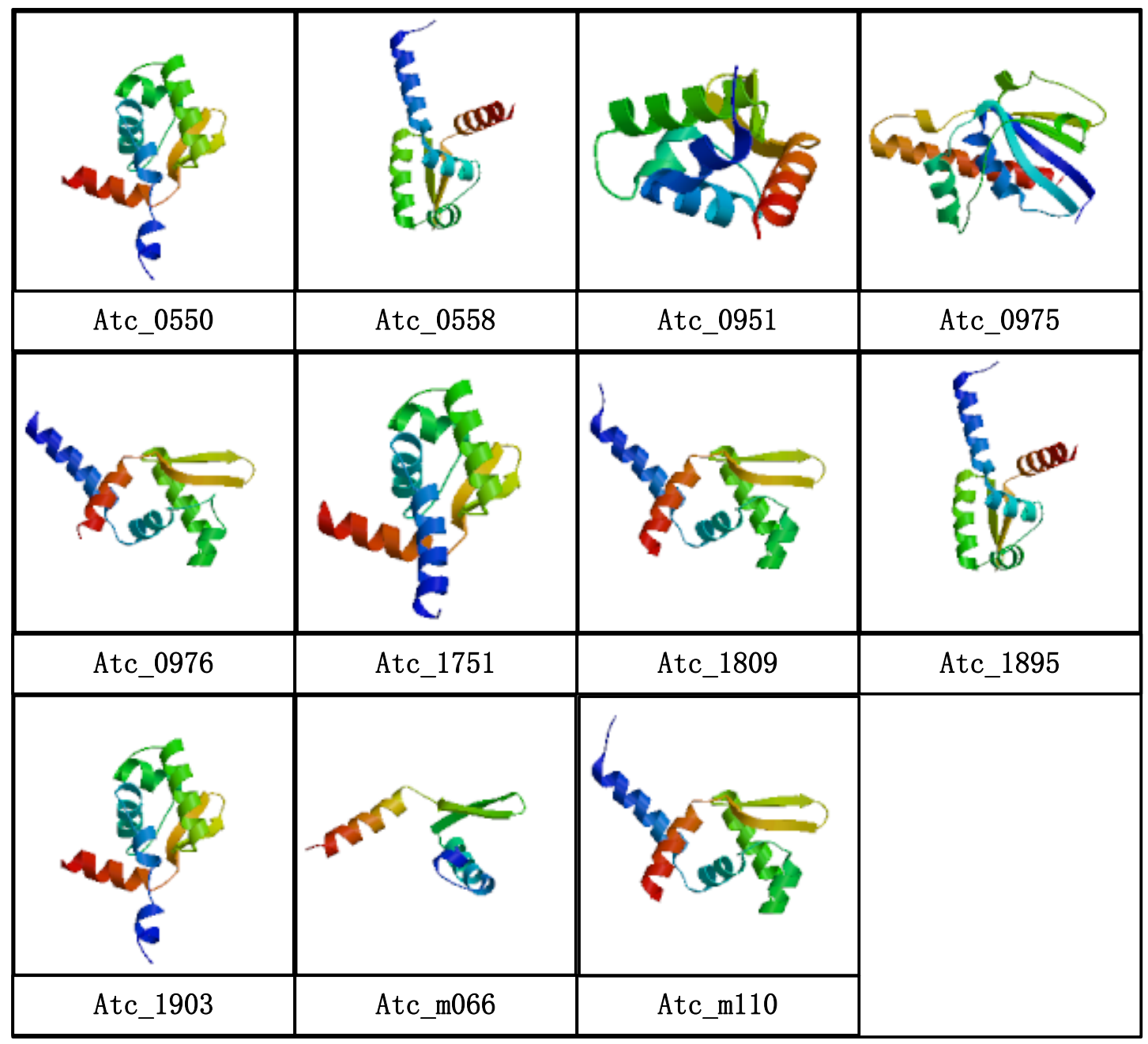

Figure 1. The tertiary structure prediction of ars genes in Acidithiobacillus caldus SM-1.

has a catalytic cysteine, Cys 12, in the active site, surrounded by an arginine triad composed of Arg 60, Arg 94, and Arg 107 (Martin et al., 2001). This native structure utilized the chemistry of the Cys in concert with at least three arginines to trap the arsenate in three binding pockets. Compared with our predicted result of binding sites of ArsC-As, there was a certain similarity between amino acid residues, and they both provided with three Arg residues. Transcription of the ars operon was negatively regulated by the ArsR proteins and induced by the arsenite. Cysteines in the ArsR protein comprised part of a metal binding motif found in members of the ArsR family of metalloregulatory proteins (Shi et al., 1994). In this study, DNA-binding residues of six ArsR proteins contained two cysteine residues, respectively. However, it was reported that an atypical ArsR regulator from $A$. ferrooxidans, which was able to respond to arsenic, did not contain the conserved metal-binding motif (Butcher and Rawlings, 2002). It implied that ArsR regulators may have a different method of binding the inducer.

A. caldus is one of the four members ( $A$. caldus, $A$. thiooxidans, $A$. ferrooxidans and $A$. ferrivorans) of the genus Acidithiobacillus characterized to date whose shared metabolic and functional capabilities allow them to survive in extremely acidic environments (Valdes et al., 2011; Liljeqvist et al., 2011; Valdes et al., 2008; You et al., 2011). Genome analysis revealed a closer functional relatedness of $A$. caldus to $A$. thiooxidans than to $A$. ferrooxidans and $A$. ferrivorans (Valdes et al., 2011). In this paper, phylogeny analysis showed that these four members of the genus Acidithiobacillus seems to share the same evolutionary origin in arsenic resistance system. However, the iron-oxidizing bacterium of the genus Leptospirillum formed a weak supported group with $A$. caldus based on phylogeny analysis of ArsB and ArsC sequences data in this study. These results provide new opportunities for experimental research and contribute to a better understanding of arsenic resistance system of $A$. caldus SM-1. 


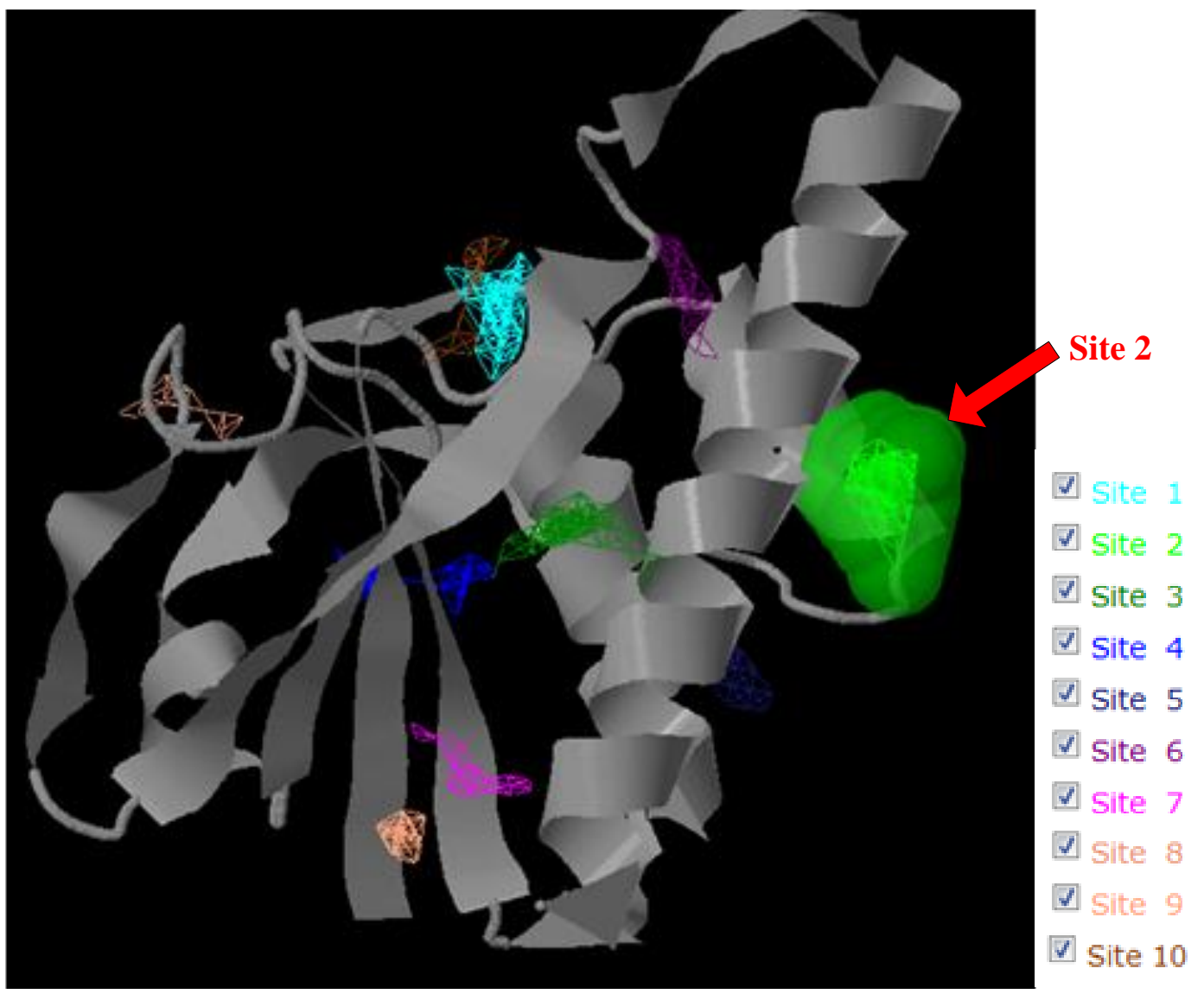

Figure 2. The structure of ten binding sites of ArsC model in A. caldus SM-1. Second binding site was composed of six residues Leu 52, Arg 55, Glu 56, Tyr 125, Arg 126 and Arg 129, and implied as the binding site of ArsC-As in A. caldus SM-1.

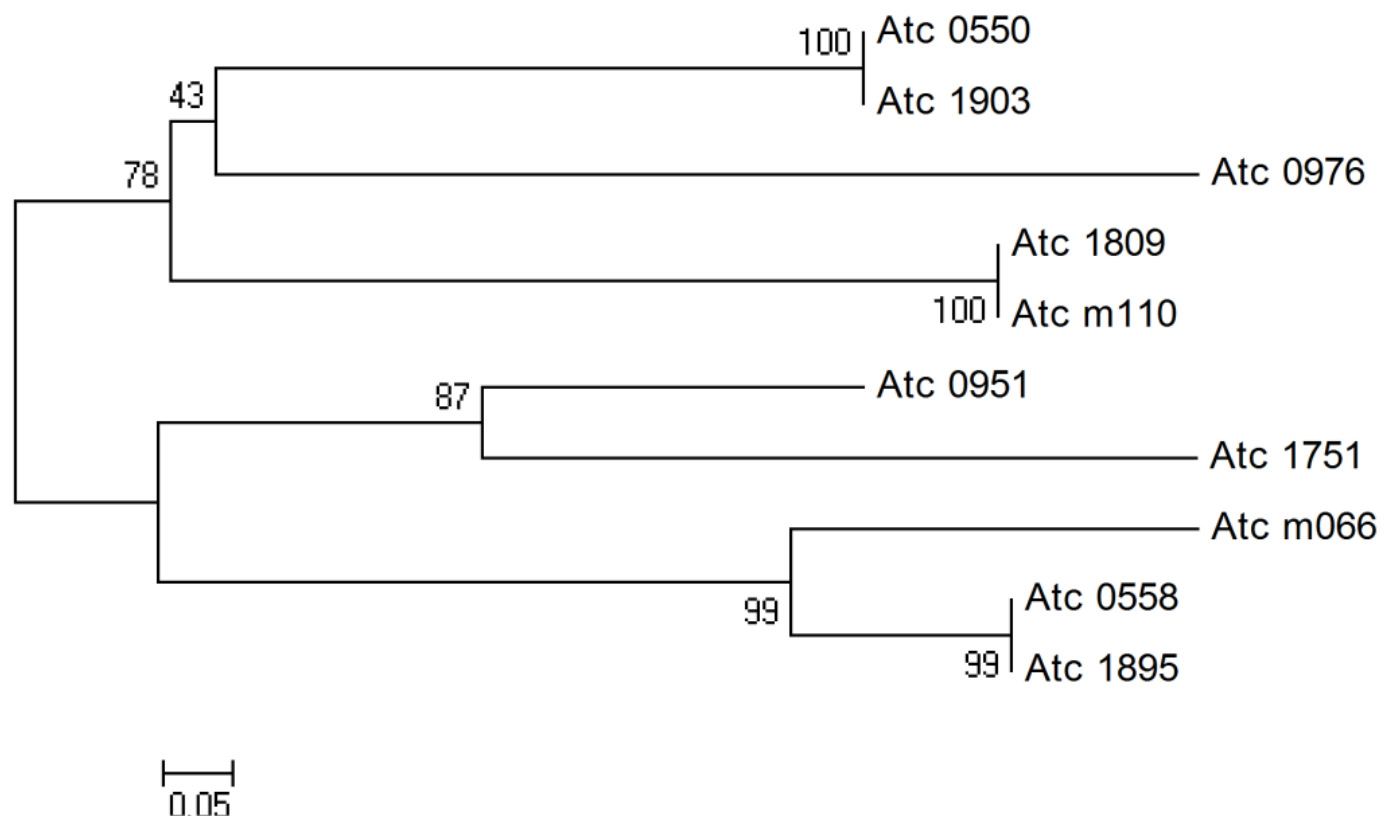

Figure 3. Phylogenetic tree based on the sequences of ArsR proteins in Acidithiobacillus caldus SM-1. 


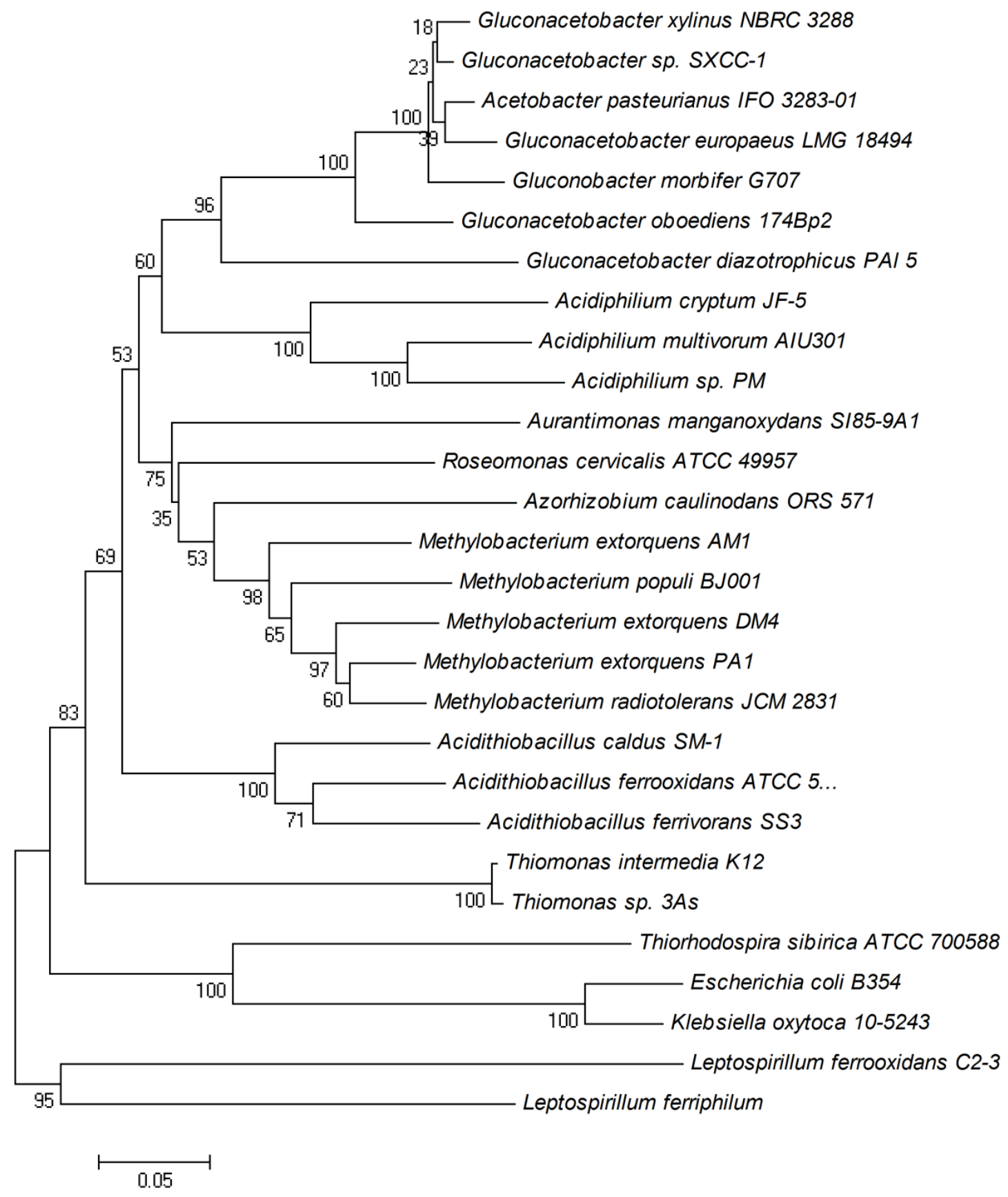

Figure 4. Phylogenetic tree based on the sequences of ArsB protein.

To study the ecological relationships of biomining bacteria and the population dynamics during the bioleaching processes, specific methods for their identification and enumeration are required. Conventional plate count methods and biochemical identification methods described previously could not circumvent the problems linked to the long wait for the colony to develop and/or the inability of some bacteria to grow on solid media (Johnson, 1991; Ahmad, 1993). In recent years, various nucleic acid-based molecular methods, such as
Polymerase chain reaction (PCR) method (Feng et al., 2012; Escobar et al., 2008; Kamimura et al., 2001; DeWulfDurand et al., 1997) and fluorescent in situ hybridization (FISH) (Mahmoud et al., 2005), have been developed for the rapid detection and identification of Acidithiobacillus strains because of simplicity in operation, stable detection results, and savings in time. A high level of marker specificity is crucial for various nucleic acid-based molecular methods. In this study, the nucleotide sequence of Atc_0558 was identified as 


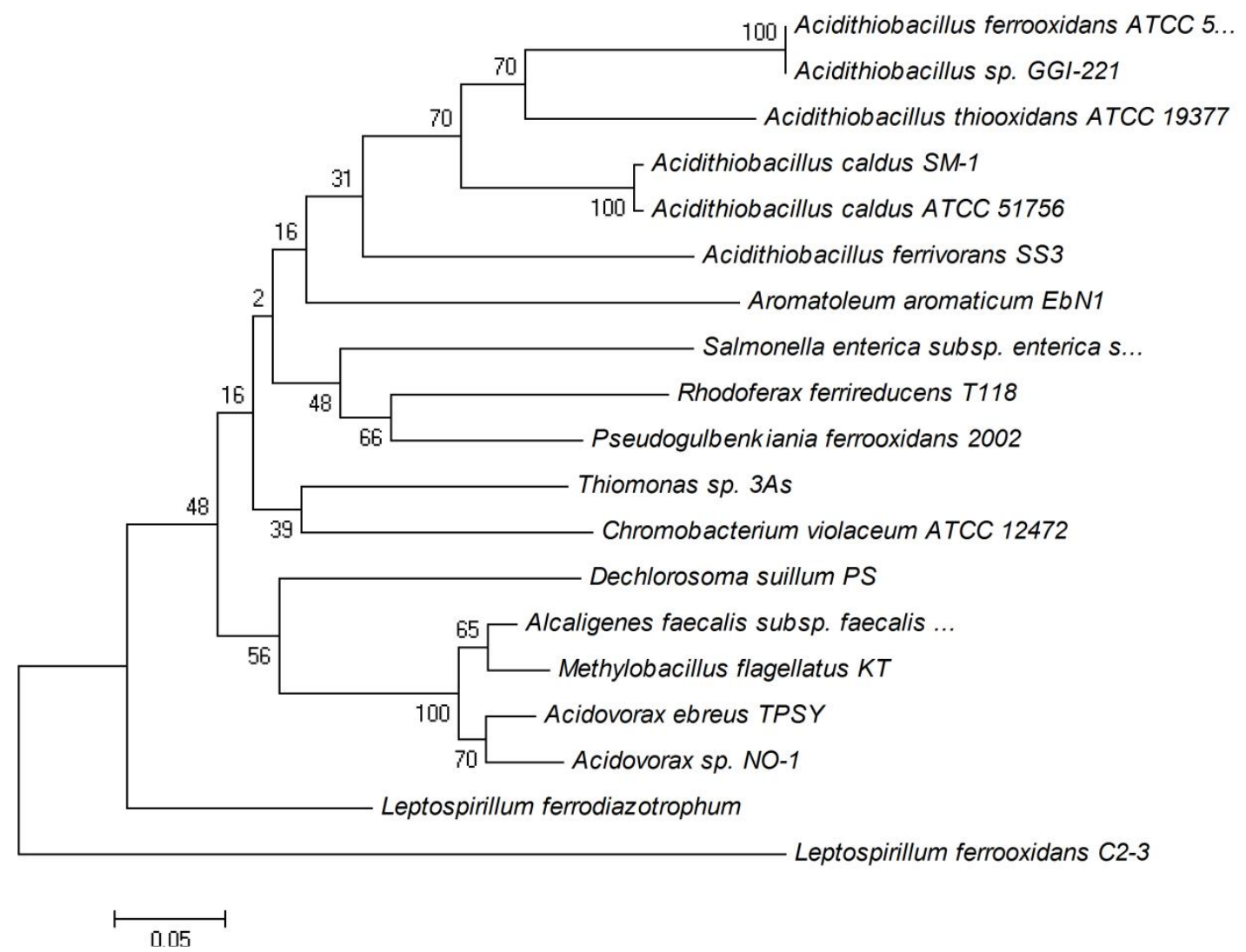

Figure 5. Phylogenetic tree based on the sequences of Ars C protein.

specific marker gene of $A$. caldus SM-1, which had a potential to be developed for new molecular methods for rapid identification of $A$. caldus SM-1. Further researches on this strain-specific marker will be carried out subsequently.

The distribution of genes on chromosome was one of decisive factors of gene functions. In this study, we found that 10 ars genes were intently localized in the chromosomes of $A$. caldus SM-1, implying an inducible, chromosomally encoded arsenic-resistance mechanism. This ancestral arrangement suggested that $A$. caldus has evolved a variety of mechanisms for coping with arsenic toxicity. Moreover, different dimensional structure determined functional discriminations. In silico threedimensional structure analysis revealed that three major types of three-dimensional structures, interestingly, broadened horizons for further physiological or functional studies of ars genes in A. caldus SM-1.

In conclusion, we present systematic bioinformation of in silico 12 ars genes that might be involved in arsenic resistance system in $A$. caldus SM-1. The secondary structure analysis and physical and chemical properties comparative information of ars genes could be a valuable resource for further molecular functional studies and electrophysiological researches of ars genes. Our bioinformatics analysis of ars genes should help in probing to the arsenic resistance of $A$. caldus SM-1.

\section{ACKNOWLEDGEMENTS}

This work was jointly supported by the grant No. 2012BAC11B07 and 51064007 from the National Key Technology R\&D Program of China, and the grant No. 20121BBG7004, 20111bdh80032 and 20114BAB213019 from the Natural Science Foundation of Jiangxi Province, China.

\section{REFERENCES}

Achour-Rokbani A, Cordi A, Poupin P, Bauda P, Billard P (2010). Characterization of the ars gene cluster from extremely arsenicresistant Microbacterium sp. strain A33. Appl. Environ. Microbiol. 76:948-955.

Ahmad MK, Tmbamu (1993). An improved solid medium for isolation, enumeration and genetic investigations of autotrophic iron-and sulphur-oxidizing bacteria. Appl. Microbiol. Biot. 39:259-263.

Benkert P, Biasini M, Schwede T (2011). Toward the estimation of the absolute quality of individual protein structure models. Bioinformatics 27:343-350.

Butcher, BG, Rawlings DE (2002). The divergent chromosomal ars operon of Acidithiobacillus ferrooxidans is regulated by an atypical ArsR protein. Microbiology. 148:3983-3992.

Cervantes C, Ji G, Ramirez JI, Silver S (1994). Resistance to arsenic 
compounds in microorganisms. FEMS Microbiol. Rev. 15:355-367.

Combet C, Blanchet C, Geourjon C, Deleage G (2000). NPS@: network protein sequence analysis. Trends Biochem. Sci. 25:147-150.

DeWulfDurand P, Bryant Lj, Sly Li (1997). PCR-mediated detection of acidophilic, bioleaching-associated bacteria. Appl. Environ. Microbiol. 63:2944-2948.

Dianne K, Newman D (1998). A brief review of microbial arsenate respiration. J. Geomicrobiol. 15:255-268.

Dopson M, Lindstrom EB (1999). Potential role of thiobacillus caldus in arsenopyrite bioleaching. Appl. Environ. Microbiol. 65:36-40.

Dopson, M, Lindstrom EB, Hallberg KB (2001). Chromosomally encoded arsenical resistance of the moderately thermophilic acidophile Acidithiobacillus caldus. Extremophiles 5:247-255.

Escobar B, Bustos K, Morales G, Salazar O (2008). Rapid and specific detection of Acidithiobacillus ferrooxidans and Leptospirillum ferrooxidans by PCR. Hydrometallurgy 92:102-106.

Feng, S, Xin Y, Yang H, Zhang L, Kang W, Xia X, Wang W (2012). A novel and efficient assay for identification and quantification of Acidithiobacillus ferrooxidans in bioleaching samples. J. Ind. Microbiol. Biotechnol.

Hallberg, KB, Lindstrom EB (1994). Characterization of Thiobacillus caldus sp. nov., a moderately thermophilic acidophile. Microbiology 140(12):3451-3456.

Huber R, Sacher M, Vollmann A, Huber H, Rose D (2000). Respiration of arsenate and selenate by hyperthermophilic archaea. Syst. Appl. Microbiol. 23:305-314.

Ji G, Silver S (1992). Reduction of arsenate to arsenite by the ArsC protein of the arsenic resistance operon of Staphylococcus aureus plasmid pl258. Proc. Natl. Acad. Sci. U. S. A. 89:9474-9478.

Johnson D, Barrie SM (1991). A highly effecient and universal solid medium for growing mesophilic and moderately thermophilic, ironoxidizing, acidophilic bacteria. J. Microbiol. Meth. 13:113-122.

Kamimura K, Wakai S, Sugio T (2001). Identification of Thiobacillus ferrooxidans strains based on restriction fragment length polymorphism analysis of 16S rDNA. Microbios 105:141-152.

Kotze AA, Tuffin IM, Deane SM, Rawlings DE (2006). Cloning and characterization of the chromosomal arsenic resistance genes from Acidithiobacillus caldus and enhanced arsenic resistance on conjugal transfer of ars genes located on transposon TnAtcArs. Microbiology 152:3551-3560.

Laurie AT, Jackson RM (2005). Q-SiteFinder: an energy-based method for the prediction of protein-ligand binding sites. Bioinformatics 21:1908-1916.

Li B, Lin J, Mi S (2010). Arsenic resistance operon structure in Leptospirillum ferriphilum and proteomic response to arsenic stress. Bioresour. Technol. 101:9811-9814.

Liljeqvist M, Valdes J, Holmes DS, Dopson M (2011). Draft genome of the psychrotolerant acidophile Acidithiobacillus ferrivorans SS3. J. Bacteriol. 193:4304-4305.

Ma X, Guo J, Liu HD, Xie JM, Sun X (2012). Sequence-based Prediction of DNA-binding Residues in Proteins with Conservation and Correlation Information. IEEE/ACM Trans. Comput. Biol. Bioinform. 9(6):1766-1775.

Mahmoud KK, Leduc LG, Ferroni GD (2005). Detection of Acidithiobacillus ferrooxidans in acid mine drainage environments using fluorescent in situ hybridization (FISH). J. Microbiol. Methods. 61:33-45.

Martin P, Demel S, Shi J, Gladysheva T, Gatti DI, Rosen BP, Edwards BF (2001). Insights into the structure, solvation, and mechanism of ArsC arsenate reductase, a novel arsenic detoxification enzyme. Structure, 9:1071-1081.

Muller D, Lievremont D, Simeonova DD, Hubert JC, Lett MC (2003). Arsenite oxidase aox genes from a metal-resistant betaproteobacterium. J. Bacteriol. 185:135-141.

Nakai K, Horton P (1999). PSORT: a program for detecting sorting signals in proteins and predicting their subcellular localization. Trends. Biochem. Sci. 24:34-36.

Petersen TN, Brunak S, Von Heijne G, Nielsen H (2011). SignalP 4.0: discriminating signal peptides from transmembrane regions. Nat. Methods 8:785-786.
Rawlings DE, NJ Coram, MN Gardner, SM Deane (1999). Thiobacillus caldus and Leptospirillum ferrooxidans are widely distributed in continuous flow biooxidation tanks used to treat a variety of metal containing ores and concentrates. In R. Amils and A. Ballester (ed.), Biohydrometallurgy and the environment toward the mining of the 21st century, part A. Elsevier, Amsterdam, The Netherlands 777-786.

Saltikov CW, Newman Dk (2003). Genetic identification of a respiratory arsenate reductase. Proc. Natl. Acad. Sci. U. S. A., 100:1098310988.

Santini JM, Sly LI, Schnagl RD, Macy JM (2000). A new chemolithoautotrophic arsenite-oxidizing bacterium isolated from a gold mine: phylogenetic, physiological, and preliminary biochemical studies. Appl. Environ. Microbiol. 66:92-97.

Shi W, Wu J, Rosen BP (1994). Identification of a putative metal binding site in a new family of metalloregulatory proteins. J. Biol. Chem., 269:19826-19829.

Stolz JF, Oremland RS (1999). Bacterial respiration of arsenic and selenium. FEMS Microbiol. Rev. 23:615-627.

Tamura K, Dudley J, Nei M, Kumar S (2007). MEGA4: Molecular Evolutionary Genetics Analysis (MEGA) software version 4.0. Mol. Biol. Evol. 24:1596-1599.

Tuffin IM, De Groot P, Deane SM, Rawlings DE (2005). An unusual Tn21-like transposon containing an ars operon is present in highly arsenic-resistant strains of the biomining bacterium Acidithiobacillus caldus. Microbiology 151:3027-3039.

Valdes J, Ossandon F, Quatrini R, Dopson M, Holmes DS (2011). Draft genome sequence of the extremely acidophilic biomining bacterium Acidithiobacillus thiooxidans ATCC 19377 provides insights into the evolution of the Acidithiobacillus genus. J. Bacteriol. 193:7003-7004.

Valdes J, Pedroso I, Quatrini R, Dodson RJ, Tettelin H, Blake R, 2nd Eisen JA, Holmes DS (2008). Acidithiobacillus ferrooxidans metabolism: from genome sequence to industrial applications. BMC Genomics 9:597.

Wilkins MR, Gasteiger E, Bairoch A, Sanchez JC, Williams KL, Appel RD, Hochstrasser DF (1999). Protein identification and analysis tools in the ExPASy server. Methods Mol. Biol. 112:531-552.

You, XY, Guo X, Zheng HJ, Zhang MJ, Liu LJ, Zhu YQ, Zhu B, Wang SY, Zhao GP, Poetsch A, Jiang CY, Liu SJ (2011). Unraveling the Acidithiobacillus caldus complete genome and its central metabolisms for carbon assimilation. J. Genet. Genomics 38:243252 